\title{
The Evidence Supporting a Systematic Approach to the Care of the Injured Patient:From Prevention to Rehabilitation 1
}

\author{
Moishe Liberman $\mathrm{MD}^{\dagger}$, David S Mulder MD ${ }^{\dagger}$, John S Sampalis $\mathrm{PhD}^{*}$
}

\section{INTRODUCTION}

Trauma is the leading cause of death for individuals under 45 years of age in the Western world and remains the fourth leading cause of death for all ages combined $(1,2,3,4)$. Approximately 0.9 million people worldwide die secondarily to injury ( $8 \%$ of all deaths) (5). It is also a major cause of morbidity in both the short and long-term (6). Furthermore, injury is a leading cause of disability, potential years of life lost and a major contributor to overall health care costs $(7,8,9)$. It is estimated that injury causes 36 life-years lost per death compared to 16 life-years for cancer and 12 years for heart disease and stroke combined (10). In 1994, 8,687 people died following accidents in Canada (1). Approximately four times as many patients suffer severe disability related to accidents each year.

The cost of acute medical care for injured patients is in excess of $\$ 16$ billion per annum (11). This represents the second largest source of medical expenditures in the United States. In addition to the health dollars spent on the acute care of injured patients, an additional $\$ 150$ billion US are required to cover the annual cost due to death, disability, and lost wages and taxes (9). From a health-economic perspective, the cost of trauma and its consequences makes the elucidation of evidence-based practices paramount. Trauma care systems have been

*To whom correspondence should be addressed: Moishe Liberman McGill University Health Centre, Montreal General Hospital Departments of Surgery and Clinical Epidemiology

1650 Cedar Avenue, L10-520 Montreal, Quebec, Canada H3G 1A4 phone: (514) 934-6116, fax: (514) 934-9913

e-mail: moishe.liberman@mail.mcgill.ca

$\dagger$ Montreal General Hospital - Department of Surgery, McGill University Health Center

§Montreal General Hospital - Department of Clinical Epidemiology, McGill University Health Center

$¥$ Hôpital Sacre Coeur - Department of Surgery, Université de Montreal, Montreal, Quebec, Canada shown to significantly decrease medical care costs. It is estimated that by extending trauma care systems throughout the entire United States, annual medical care payments could be lowered by $\$ 3.2$ billion (12). If productivity costs due to premature death are taken into account, the total savings could total $\$ 10.3$ billion.

\section{TRAUMA SYSTEMS}

Trauma care throughout Canada and the rest of North America has seen tremendous changes over the last 30 years. The regionalisation of trauma care, which has occurred in some Canadian and American regions, has shifted the scope of trauma patient management from hospital-based care to a systems approach. A regionalised approach to trauma care (a trauma system) consists of the global care of the injured patient, from the time of injury until the end of rehabilitation $(13,14)$. The system provides a continuum of services encompassing four elements: [1] pre-hospital care, [2] in-hospital care [3] rehabilitation, and [4] research. The ultimate goal of these systems is to get the injured patient to definitive care as soon as possible $(15,16)$.

Trauma systems have been designed to render "optimal care" to injured patients. Eggold defines optimal care as being based on two implied premises (17): One premise is that suboptimal trauma care is possible and demonstrable and the other premise is that optimal care must result in reduced mortality and/or morbidity, "the sine qua non of medical progress". Furthermore, by pooling resources and avoiding duplication through a system of care within a region, cost effectiveness is assured (18).

The care of injured patients is a continuum from the moment of injury, until the return to daily life $(19,20)$. Regionalised trauma care incorporates several different elements, which together make up the trauma "system". 
These systems have been repeatedly shown to decrease mortality and improve the outcome of injured patients in multiple different regions throughout the Western world.

\section{EPIDEMIOLOGY OF TRAUMA DEATHS}

Trauma is a devastating disease. It contributes to approximately 140,000 deaths per year in the United States (21). Unintentional injuries account for $4.6 \%$ of deaths and $19.6 \%$ of potential years of life lost in patients younger than 65 years of age. (22) Injuries account for $61 \%$ of deaths due to trauma in the United States and nearly half of these deaths are due to motor vehicle accidents (7). Falls, occurring mostly in the octogenarian population, account for the second most prevalent portion of unintentional deaths.

Death resulting from trauma follows a trimodal distribution $(19,23,24,25,26)$. These peaks were first alluded to in reports by Beebe and DeBakey in 1952 (27) and by Zollinger in 1955 (28) and later expanded on by Trunkey in 1983 (19). The first peak of death following injury is dubbed the "immediate deaths" and occurs within seconds of injury. It accounts for $50 \%$ of trauma-related mortality. These early deaths occur secondary to lacerations to the brain, upper spinal cord, heart, aorta and other major vessels. Virtually all of these patients die and little, if anything, can be done to save them. Cales showed that $44 \%$ of trauma deaths occurred at the scene (29). The only way to reduce deaths in the first peak of trauma mortality is through prevention strategies and programs, as well as tougher legislation on firearms and motor vehicle traffic laws (30). Injury prevention and control has been shown to have more immediate health and economic benefits than the prevention and control of chronic diseases (31).

The second peak of mortality, the "early deaths" occurs within minutes to a few hours following injury and contributes to $30 \%$ of mortality following trauma. This period has been dubbed the "golden hour" following injury (19). Deaths in this period are secondary to injuries that require urgent and emergent care. These injuries are time-critical and the sooner the patient receives definitive care for these injuries, the better the outcome. Important injuries in this category include: subdural and epidural hematomas, hemopneumothorax, liver lacerations, ruptured spleen, pelvic and long bone fractures causing significant bleeding, as well as injuries to blood vessels contributing to significant blood loss. These injuries require timely definitive care, usually through surgery to repair the source of blood loss and stop the hemorrhage or to evacuate a compressive hematoma (cerebral hemorrhage), or an interventional procedure (tube thoracostomy, pericardiocentesis, angioembolisation...). If these procedures are not provided promptly and properly by the appropriate personnel in the appropriate setting, mortality occurs.

It is for the patients in the second period of trauma deaths that systematic trauma care attempts to make an impact. These are the time-critical patients, desperately in need of definitive and appropriate care in a timely manner. Patients receiving rapid transport to hospital will not have good outcomes if they are taken to the wrong hospital. Patients taken to the right hospital will also have poor outcomes if there is a delay in getting them there. The second peak is the focus of trauma systems and regionalised care of the injured patient.

The third peak of mortality following trauma, the "late deaths", occurs several days or week following injury. These deaths account for approximately $20 \%$ of deaths after injury. Deaths in this period are usually secondary to sepsis and multiple organ system failure. Rapid and appropriate care can reduce these injuries, however most of these deaths will occur regardless of the system of trauma care and the key to reducing them lies in research into systemic mediators of sepsis and multiple organ dysfunction. Time is less of a factor in the outcome of these patients; rather, the quality of medical care and the state of medical knowledge contribute to outcome in these patients.

Recently researchers have identified a fourth peak of trauma deaths, which requires further study. The fourth peak of deaths is that which occurs in the first year following injury (32). The age characteristics of this unique group of patients show that patients over the age of 65 have a 15 -fold greater chance of dying in the year following injury.

\section{PROCESS OF REGIONALISATION, BUILDING A "TRAUMA SYSTEM"}

The basis for the regionalisation of trauma care or the development of a "trauma system" is the need to link all aspects of care in order to maximize efficiency, pool resources and improve outcomes. A comprehensive trauma system links hospitals, pre-hospital care and other emergency medical services, post hospital care facilities (rehabilitation and long-term care centres), as well as health care and public safety agencies (33). Ideal trauma systems include prevention, access, acute hospital care, rehabilitation, and research activities (34). These systems have been developed in order to direct seriously injured patients to specific facilities on local, regional, and state/province wide bases. The two main goals of regionalised trauma care are to improve the quality of care and to decrease its cost (35).

The American College of Surgeons Committee on Trauma clearly outlines the importance of emphasising the trauma system, rather than the trauma centre as being integral in improving trauma patient outcome 
(34).

"Care of the injured patient requires a system approach to ensure optimal patient care. A systematic approach is necessary within a facility; however no one trauma centre can do everything alone. Thus, a system approach is necessary within an entire community regardless of its size...If resources for optimal care of the injured patient are to be used wisely, then some concentration of resources should occur. This type of resource allocation should allow patients to move to the highest level of care available and, ideally, should also avoid excessive and inappropriate expenditure in a time of limited medical resources."

Integral to the trauma care system is the designation of definitive trauma care facilities. These facilities provide the full spectrum of trauma care to injured patients in the most efficient and effective manner. The overall goal of the system is patient care and outcome, however efficiency and proper use of resources is emerging as an important aspect of trauma systems. Every trauma system or regionalised trauma area should have a "lead hospital". The lead hospital should be the hospital with the highest level of care (highest designation) in the area.

Trauma centres serve as the hubs of these systems. Trauma centres also exist in areas without formal trauma systems in place. In these areas they are usually not designated as trauma centres, but act as "de facto" or "functional" centres (36). Tertiary trauma centres (level I centres) are responsible for receiving the most seriously injured patients directly from the field (in most cases), as well as accepting and guiding transfer from secondary and primary centres. They also serve the purpose of being leaders in trauma care and prevention programs for the region. They are also responsible for conducting trauma-related research.

West identified eight essential elements that were integral to an inclusive trauma system based on criteria from the American College of Surgeons (37). These criteria were: (a) the presence of a lead agency with legal authority to designate trauma centres; (b) the use of a formal process for trauma centre designation; (c) the use of American College of Surgeons standards for trauma centres; (d) the use of an out-of-area survey team for trauma centre designation; (e) limiting the number of designated trauma centres in a community based on assessment of population need; (f) the application of written triage criteria that form the basis for bypassing non-trauma centre hospitals; (g) the presence of ongoing monitoring systems for trauma centres; and (h) the state-wide availability of trauma centres.

The integral steps in developing a regional trauma system are (37):

\section{Basic Data}

The first step is defining the magnitude of the problem in the area to be regionalised. This can be carried out using autopsy studies $(38,39)$, preventable death studies (40), and/or regional trauma reviews (41). Out-of region experts should be recruited in order to provide objective assessments of the system in place.

\section{Develop a Comprehensive Regional Plan}

The regional plan should deal with patient care from the time of injury until the end of their rehabilitation. It should be based on guidelines from the American College of Surgeons $(42,43,44)$ and have local surgeons heavily involved in planning and development.

The plan should address the following issues:

- Pre-hospital Care

- Air Transport

- Triage

- Trauma Centre Designation

- Quality Assurance

- Specialty Care Programs

- Research

- Rehabilitation

- Prevention and Public Education

- Disaster Planning

\section{Identify Barriers to Change}

By identifying barriers to changes prior to attempted implementation, a young system can develop strategies to overcome these changes. The major barriers to change are usually economic.

\section{Develop a Management Structure}

A lead agency must be identified and given formal, legal authority for trauma centre designation.

\section{How to Implement the Plan}

Once the plan has been developed, all regional hospitals should be encouraged to participate and undergo formal verification.

An "inclusive" approach to trauma system design has been adopted by trauma system planners (45). This approach is designed to improve the quality of care provided to injured patients by developing strategies for overcoming problems of access, cost and variation in the quality of services. Planning and implementing a system of trauma care is a huge undertaking (46). It requires intensive study, coordination and financial commitment. In the United States, the problem of access for patients without health insurance and those in rural areas have become paramount to the 
"inclusive" system. These problems are constantly being investigated and commitment on the part of systems for the care of these patients are vital to the success of these systems in the future.

\section{THE ELEMENTS OF A TRAUMA SYSTEM}

A model trauma care system includes the basic concept of "inclusiveness". An inclusive system encompasses all aspects of trauma from prevention of injury until the patient returns to their pre-injury baseline level of function. The key elements of regionalised trauma systems are: (1) a lead public agency with legal authority to establish and enforce trauma system policy; (2) facility categorization; (3) trauma centre designation; and (4) the implementation of triage and transfer protocols which identify patients in need of transport to definitive care at a designated trauma care centre $(47,48,49)$. Even though these elements are essential and common across all trauma systems, individual variations exist. These variations are present in the methods different communities use to design, implement and run their systems. These differences are profound in the area of the process of trauma centre designation (48). Bazzoli et al identify three key elements integral to trauma care regionalisation: pre-hospital care, organization of hospitals and inter-hospital transfer agreements (50). By assuring appropriate and timely inter-hospital transfers, patients can be appropriately treated in a system encompassing remote and rural areas (51).

The American Trauma Society (ATS) identifies four fundamental components necessary for trauma systems and eight key infrastructure elements that are critical to trauma system success (52):

\section{Fundamental Components}

- Injury Prevention

- Pre-hospital Care

- Acute Care Facilities

- Post-hospital Care

\section{Key Infrastructure Elements}

- Leadership

- Professional Resources

- Education and Advocacy

- Information Management

- Finances

- Research

- Technology

- Disaster Preparedness and Response - Conventional and Unconventional

Time-distance relationships between injured patients and definitive and appropriate care are vital to any trauma system design (53). Systems need to be created with geographic, time-transportation factors and maximum health delivery capabilities of a region in mind (54).
Another crucial element involved in maintaining an effective regionalised trauma system is quality improvement. Effective and continuous quality improvement programs depend upon concurrent monitoring of the events involved and surrounding the care of the trauma patient (21). The information for quality improvement programs is usually stored in a trauma databank, maintained either at the individual institutions within the system, or in a centralised databank for the entire system, state/province or country. Important elements to be evaluated include: facts related to the patient's injury event, injury severity, process of care and outcome.

Pre-hospital triage algorithms are integral to the optimal care for the injured patient. Injured patients need to be taken to the appropriate level facility that is prepared, properly staffed, and equipped to handle the trauma patient. Various schemes have been proposed for the pre-hospital triage of trauma patients. The most widely used is probably the American College of Surgeons Triage Algorithm $(55,34)$. Triage schemes have been shown to be effective at decreasing trauma mortality $(56,57,58)$. The algorithms outline strategies for transporting the seriously injured patient to an appropriate centre, bypassing lower level centres, which are often closer to the scene of the accident.

Trauma centres remain a key component in the systems approach to the acute care of the severely injured patient $(59,60)$. Designation of these centres is integral to improving outcomes $(36,61)$. By having designated centres committed to the resource allocation and care of injured patients, improvements in both morbidity and mortality have been demonstrated. However, the system encompasses all phases of care, from pre-hospital through acute care and rehabilitation. The creation and running of an effective system requires complete commitment from medical and allied health care professionals, as well as from regional health boards, governmental agencies and communities. Furthermore, even though the designation of trauma centres shifts more severely injured patients to designated hospitals (62), trauma centre care has been shown to significantly reduce length of stay and cost of care compared to injury severity matched patients transferred from a nontrauma facility (63). Patients directly transported to trauma centres also have less missed injuries than transferred patients (64). However, it has also been demonstrated that hospitals in remote areas that do not possess all elements necessary for the designation of trauma centres, can have similar, if not better, outcomes than those meeting criteria (65).

Surgical leadership is vital to maintaining an effective trauma system $(66,67,68)$. The American 
College of Surgeons Committee on Trauma emphasizes the role of the trauma surgeon in the design, implementation and running of a trauma system and trauma centre (34). The American Association for the Surgery of Trauma (AAST) expands on this and requires that a trauma surgeon be (69):

- Actively involved in the process of prehospital triage and treatment of trauma patients

- Thoroughly knowledgeable of the diagnostic options and treatment available in the emergency department and understands how to use them in the most appropriate and cost-effective manner

Able to prioritise and coordinate the resuscitation and treatment of multiple serious injuries while coordinating care between multiple services and subspecialties

Expert in the operative and nonoperative management of lifethreatening and limb-threatening injuries

Responsible for the comprehensive management of the injured patient in the critical care unit, including hemodynamic monitoring, ventilator management, nutrition and posttraumatic complications

Integrally involved in the rehabilitation of the injured patient.

Responsible for monitoring outcomes, identifying deficiencies in care when they exist, and correcting any identified deficiencies.

- Actively involved in trauma education, research and injury prevention. forums.

An advocate for the optimal care of trauma patients in public

Another key element in the overall running of a trauma system is prevention (44). In fact, prevention is probably the single most effective way to decrease mortality and morbidity associated with injury.

Boyd appropriately points out that in order to design and implement an effective regional trauma system, focusing on one component of the subsystem will not be as effective as an overall and comprehensive view of the sequence of events as they affect the course and final outcome (53).

\section{IN-HOSPITAL CARE - CHARACTERISTICS OF TRAUMA TREATMENT CENTRES}

The categorisation of hospitals based on their ability to care for injured patients was first suggested by Youmans and Brose in 1970 (70). They conceptualised a classification system for hospitals treating injured patients in order to assure quality of care within a community. The initial classification system comprised: "major emergency facilities", "emergency facilities" and "provisional emergency facilities". These classifications later gave birth to level I, level II and level III trauma treatment centres.

Designated trauma centres have been shown to decrease mortality, complication rates, and length of hospital stay compared to non-trauma centres $(71,72,73,74,75)$. Verification has also been shown to improve the process of care within trauma centres
$(76,77,78)$. An overview of a centre's role and requirements as part of a system of trauma care based on the ACS criteria for trauma centre designation is as follows:

\section{Level I}

Level I trauma centres are tertiary care facilities that are the focal point of a regionalised trauma system. These centres often, but not always occur in university hospitals. The facility must be capable of providing leadership and total care for every aspect of injury, from prevention to rehabilitation (59).

\section{Level II}

Level II trauma centres function in a similar capacity to level I centres, however, they do not have the extensive resources and facilities as level I centres. They are required to provide initial definitive trauma care to injured patients regardless of injury severity.

\section{Level III}

Level III centres usually occur in communities that do not have access to level I or II centres. These centres must have the capability to manage the initial care of the majority of injured patients and have transfer agreements and corridors set up for transfer of patients that exceed the hospitals resources and capabilities.

\section{Level IV}

Level IV centres are those centres treating and stabilizing injured patients in rural areas without other hospitals. They are the "de facto trauma centres" in these regions due to geographical location (59). They are responsible for providing Advanced Trauma Life Support care (55) in remote areas where no higher level of care is available prior to transfer to an advanced level centre.

The evaluation and management of severely injured patients requires significant institutional commitment and the commitment of skilled personnel (13). Recently, there has been much debate over the American College of Surgeons' requirements for minimal trauma centre volume in order for a centre to receive a designation (34). Numerous studies have been published over the last few years with conflicting results regarding the correlation between volume and outcome. Several studies have shown that volume has a positive correlation with survival $(79,80,81,79,82,83,81)$, however others have demonstrated a lack of association $(84,85,65,86,87)$. Guidelines for level I trauma centre verification require 1,200 admissions per year. Many centres in the US and Canada that cannot meet these requirements do, however, meet all other requirements for level I status.

\section{THE IMPACT OF TRAUMA CARE REGIONALISATION}

The initial fervour for trauma system implementation was backed by very few studies and lacked the large amounts of evidence that were to come over the years $(88,89)$. However, since the late 1960 s 
there have been over thirty studies demonstrating a positive impact on survival in regionalised compared to non-regionalised trauma systems (Table 1). Furthermore, the lack of a trauma care system has also been repetitively shown to contribute to substandard care and outcomes $(90,91,92,93,94)$. By centralising the care of severely injured patients in to a few highly specialized centres, as well as creating corridors for direct entry and easy exit from acute care, trauma systems significantly improve the outcome for injured patients $(46,95,96,97,98,99,100,101,102,103)$ and change the pattern of preventable mortality from delays or inadequate interventions to postoperative care errors (104). Aggregated population-based evidence $(61,71,72,73,105,106,107,108,109,110,111,112,113,11$ 4) has demonstrated a 15 to $20 \%$ improved survival rate for seriously injured patients following trauma system implementation (115).

Shackford (116) found that in the first year following establishment of a regionalised trauma system in San Diego County, severely injured patients (TS $=8$ ) had a probability of survival (Ps) of $18 \%$ compared to injured patients treated at numerous centres throughout the US and Canada (117), and an actual survival of $29 \%$. Many subsequently used this evidence in order to push healthcare systems and governments to establish organised systems of trauma care. San Diego County instituted a regionalised trauma system in 1984. Guss subsequently performed a before and after preventable death evaluation in the County $(118,119)$ using the validated autopsy review methodology proposed by West (120). Preventable death evaluation involves the calculation of a preventable death rate (PDR), which is the proportion of all deaths judged to have been preventable if optimal care had been delivered (40). Guss found that by expert panel evaluation, 2 out of 211 deaths $(1 \%)$ were preventable post regionalisation compared to 20 out of $177(11.4 \%)$ pre-regionalisation $(\mathrm{p}<0.001)$. Similar to the Orange County and San Francisco County patients, the decline in mortality post regionalisation was mostly attributed to a decline in mortality from non-central nervous system deaths.

Shackford studied the effect of regionalised trauma care on outcomes of "major trauma victims" in the first 5 months post-regionalisation and compared it to the period immediately prior to the implementation of a system in San Diego County using the medical audit committee technique for assessing optimal or suboptimal care (121). He found suboptimal care was rendered in $32 \%$ of cases prior to regionalisation, and that the implementation of a trauma system decreased the proportion to $4.2 \%$ (122). Preventable deaths occurred in $13.6 \%$ of fatalities prior to implementation, compared to $2.7 \%$ following system implementation.
Shackford subsequently looked at a subset of severely injured trauma patients (Trauma Score of $=8$ ) in the first year after trauma care regionalisation in San Diego County (121). He compared actual survival to predicted survival based on the Major Trauma Outcome Study (MTOS) (117). Following regionalisation, the probability of survival in blunt trauma patients was $18 \%$ compared to the $29 \%$ survival observed $(\mathrm{p}<0.05)$. In penetrating trauma, the probability and observed survivals were $8 \%$ and $20 \%$, respectively $(\mathrm{p}<0.05)$.

Mullins evaluated the outcomes of trauma patients before and after institution of a regionalised trauma system. The risk of death in level I trauma centres improved following implementation of a regionalised system in the North Willamette region of Oregon between 1984 and 1991 (odds ratio $=0.65$ post regionalisation) (109). The establishment of a regionalised trauma system also shifted the more seriously injured patients to the level I centres (123). Mullins then evaluated the influence of the implementation of a state-wide trauma system in Oregon on the location of hospitalisation and outcome of injured patients before and after regionalisation (110). In Oregon, following state-wide regionalisation, chances for an injured patient being admitted to a level I or II trauma centre increased and the chance of dying decreased.

A further study was done in order to attempt to control for temporal trends in advancements in medical and surgical care of injured patients (111). In this study injured patients in Oregon and Washington were compared before either state had a regionalised trauma system (1985-1988) as well as when only Oregon had a trauma system in place (1990-1993). Following trauma system implementation in Oregon, there was a significant risk reduction for death in patients with Injury Severity Scores $>15$ (Odds Ratio $=0.8, \mathrm{CI}=$ 0.70-0.91) compared to Washington. Pediatric mortality was also shown to be positively influenced by system implementation in Oregon, compared to Washington (107). Secular trends in trauma mortality are best adjusted by the types of studies that compare two systems over the same time period (124).

Kane evaluated the survival of seriously injured patients in Los Angeles County prior to (1982) and following (1984) implementation of a regionalised system of trauma care (108). There was an observed significant improvement in the adjusted odds of survival following regionalisation (odds ratio $=1.455$, $\mathrm{p}$-value $=0.048$ ) compared to the period prior to the establishment of the system. Cayten reported on mortality following motor vehicle collisions in the Hudson Valley region of New York from 1987 to 1996 
(125). There was also a significant decrease in motor vehicle collision mortality that was related and attributed to the establishment of a regionalised trauma system between 1990 and 1995 .

Nathens evaluated the effect of trauma systems throughout the United States. He looked at data from states with organized trauma systems in place and compared them to those without regionalised trauma care (126). States that contained regionalised trauma systems $(n=22)$ had a $9 \%$ lower crude mortality rate compared to those without regionalised care. After subanalysis for motor-vehicle collisions, areas with organized trauma systems had a $17 \%$ reduction in mortality compared to those without systems.

Nathens also studied the effect of regionalised trauma care on motor vehicle crash mortality throughout the United States between 1979 and 1995 (127). He found that it took approximately 10 years following regionalisation of care to start to see a decline in mortality. By 15 years, mortality from motor vehicle collisions decreased by $8 \%$. The 10-year interval between trauma system implementation and the improvement in outcomes was attributed to the necessary time for trauma system maturation, development of trauma triage protocols, inter-hospital transfer agreements, trauma centre organization, and ongoing quality assurance. These factors, however, were not assessed in this study and remain hypotheses.

Clark critically re-evaluated the aforementioned studies performed by Mullins (109), Cayten (125) and Nathens (127), which used data from the Fatality Analysis Reporting System (FARS), in order to test the accuracy of their results and assess the conclusions that were drawn regarding the effectiveness of trauma systems from these studies (128). He found that the positive impact of trauma system regionalisation was less convincing when all available data was displayed and potential confounding factors were assessed. Mortality following trauma was found to be decreasing throughout the United States and this contributed to the declining rates of mortality following injury. Clark's findings are controversial and have caused much debate (129). However, even if trauma systems do not impact on national mortality as much as some believe, they have and do definitely contribute to superior care for injured patients.

Jurkovich and Mock compared patients with serious injuries in three cities: Seattle (Washington), Monterrey (Mexico) and Kumasi (Ghana) $(130,131,132)$. Seattle is considered to have the most advanced EMS service in the world, Monterrey has a basic EMS service and Kumasi has no EMS system. Major differences also obviously existed in hospital capabilities and socioeconomic factors. Overall survival for seriously injured patients were: Kumasi $(36 \%)$, Monterrey (45\%) and Seattle (65\%). The increased survival was primarily attributed to decreased pre-hospital deaths, further highlighting the importance of the "system" in the outcome of seriously injured patients.

In July of 1998, a symposium was organized at the Skamania Lodge in Stevenson, Washington (133). The symposium was titled: "Trauma Systems - Evidence, Research, Action." The symposium was planned in order to assemble health care professionals from various disciplines to critically review the available evidence concerning trauma system effectiveness and was a huge success $(134,135)$. Prior to the symposium, a comprehensive review of the literature was undertaken by the organizing committee and key articles concerning trauma system effectiveness were selected, summarized and sent to participants (136). The articles were then critiqued by the participants at the symposium and summarized in an important paper by Mann et al. in a supplement to the Journal of Trauma (10). Mann concluded that there was evidence supporting the effectiveness of regional trauma care systems in reducing in-hospital mortality. However, further outcome studies were required including studies based on 30-day post discharge mortality and the evaluation of morbidities.

Outcomes have also been shown to improve as time passes following establishment of a trauma system $(137,138,139)$. As the system matures, mortality for severely injured patients declines. O'Keefe was able to show a positive survival advantage for injured patients with ISS $=16$ over 10 years at a single level I trauma centre between 1986 and 1995 (140).

The effects of regionalisation in Canada have not been as extensively studied as the systems of trauma care in the United States. However, the impact of regionalisation on the outcome of trauma patients in the province of Quebec has been studied in depth over the last 15 years $(58,93,138,141,142)$. Regionalisation of trauma care has been shown to significantly improve outcome for seriously injured patients in Quebec.

In the early years of trauma care regionalisation, designation of trauma care centres does not lead to increases in patient volume at designated trauma centres. Instead, there is a redistribution of patients, with the more severely injured patients being transported to the higher level centres $(29,143)$. However, once a system becomes established and is running efficiently, outcomes improve (137) and proportions of trauma patients being transported to higher level centres increase $(144,145)$. The increase in patients is usually secondary to the triage and transport of patients with low injury severity injuries. Pre-hospital care workers and dispatchers prefer 


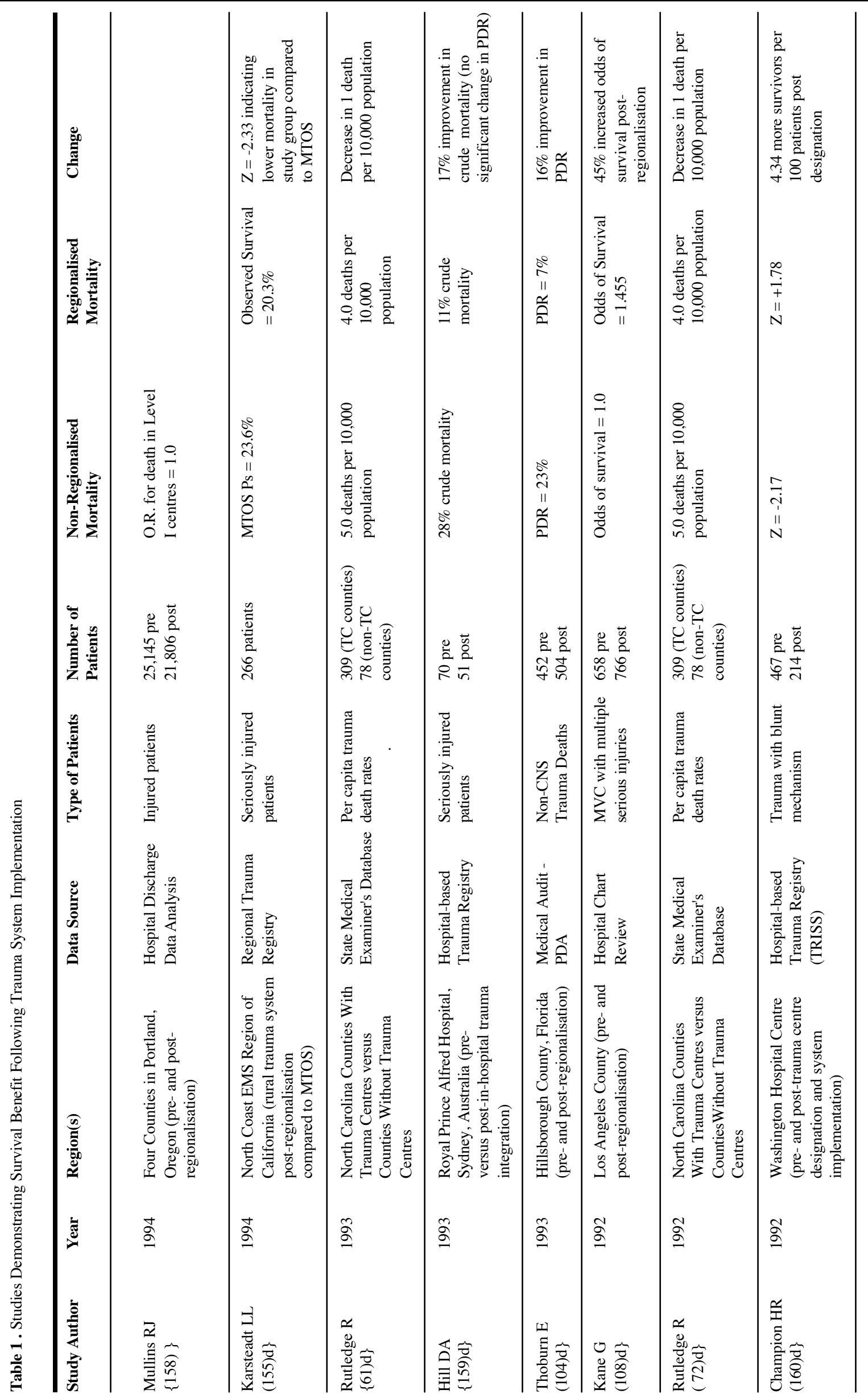




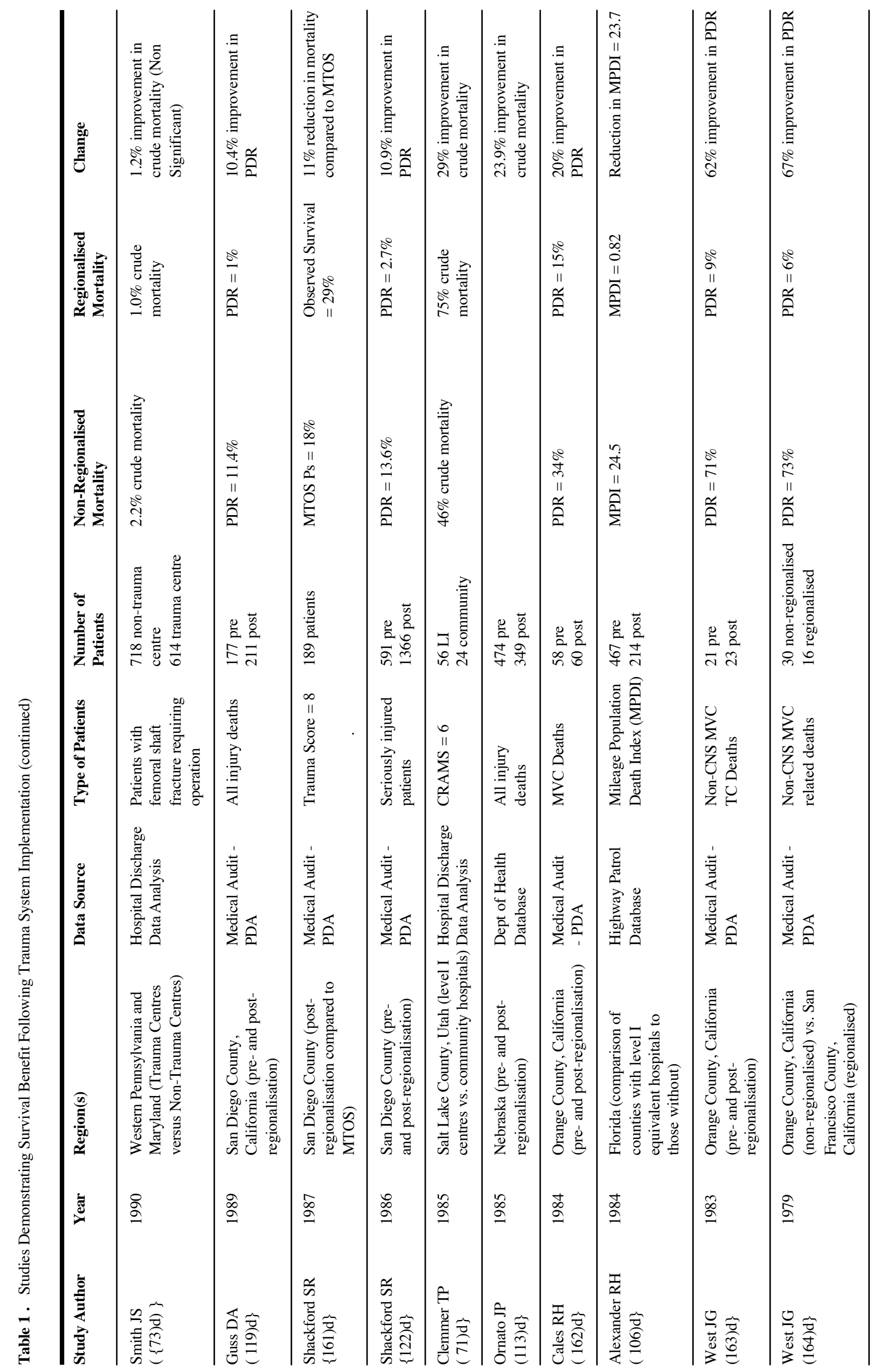




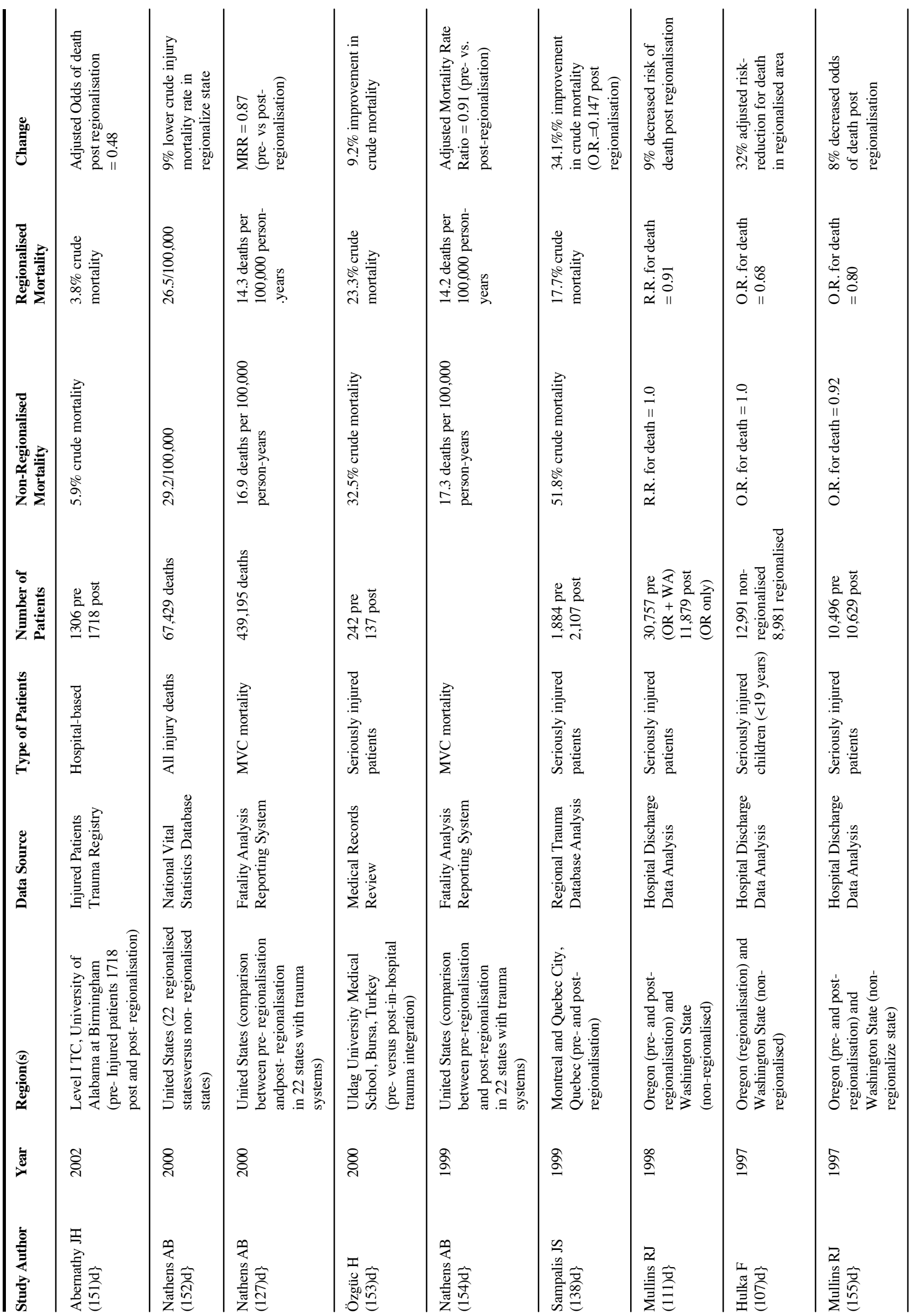




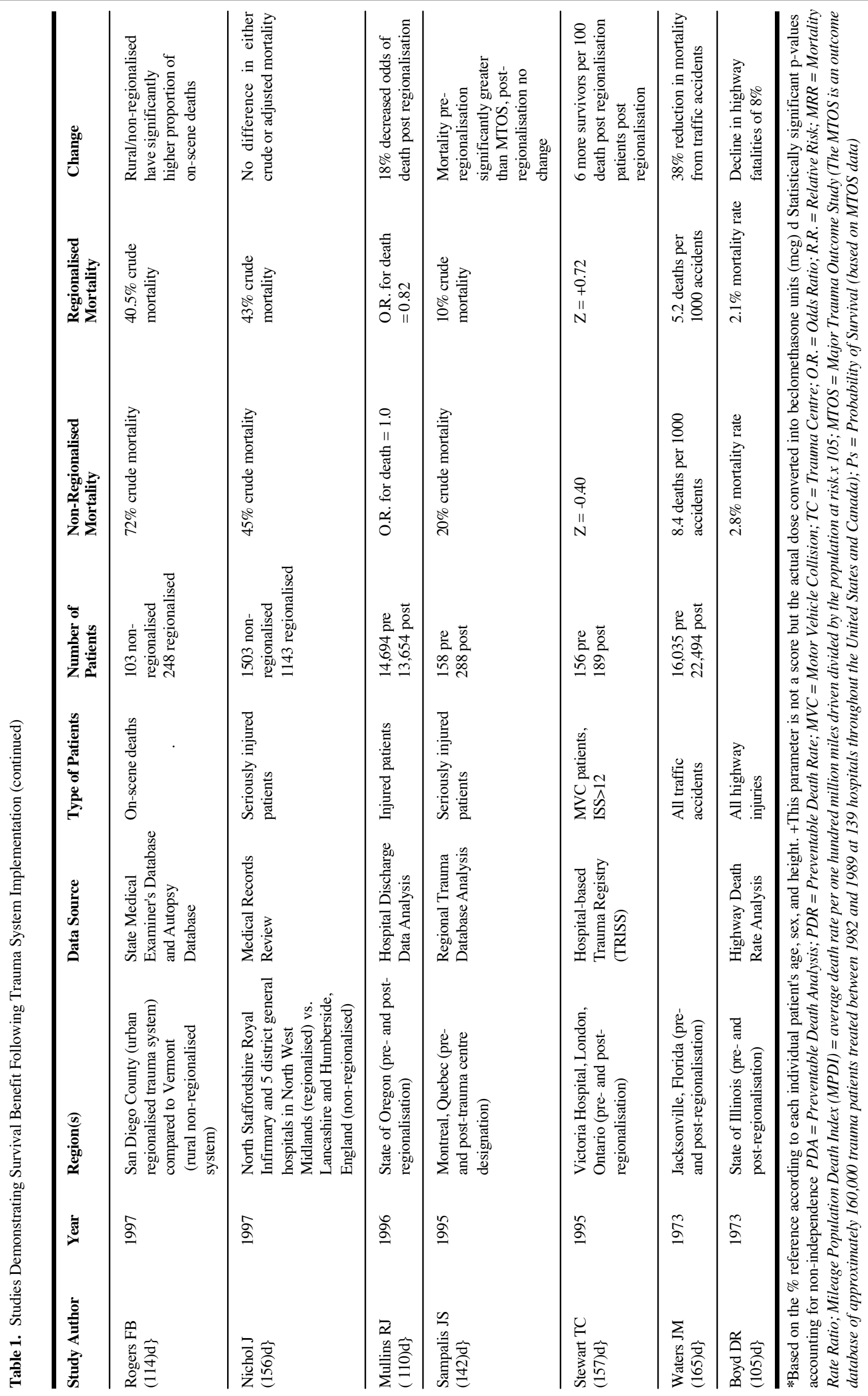


to err on the side of over-triage in order not to miss significant occult injuries $(146,147)$. Furthermore, triage algorithms are designed to over-triage less severely injured patients $(43,148,149,150)$. These factors contribute significantly to the high costs of running a level I trauma centre (48).

\section{CONCLUSION}

Regionalisation of trauma care improves outcome for injured patients by utilizing a systematic approach to the care of the injured patient. This approach encompasses all phases of injury from prevention to rehabilitation. A systematic approach to the care of the trauma patient is based on cooperation between prehospital emergency medical services, hospitals of all levels, rehabilitation facilities and local, regional, statewide/provincial and national organizations. By pooling resources and emphasizing teamwork and cooperation, trauma systems have changed the face of trauma patient care, significantly decreased morbidity and mortality secondary to injury and set a benchmark for the regionalised approach to patient management for other areas of healthcare.

\section{REFERENCES}

1. Health Reports 1995. Statistics Canada, 1995.

2. Mortality. Summary List of Causes, Vital Statistics. Health Division, Vital Statistics and Health Status Section. Ottawa: Statistics Canada, 1986.

3. Mortality. Summary List of Causes, Vital Statistics. Health Division, Vital Statistics and Health Status Section. Ottawa: Statistics Canada, 1987.

4. Mortality. Summary List of Causes, Vital Statistics. Health Division, Vital Statistics and Health Status Section. Ottawa: Statistics Canada, 1988.

5. Gupta Kj, Parr MJA, and Nolan JP. Epidemiology of trauma The role of the anesthesiologist. Anesth Clin N Am 1999;17:1732.

6. MacKenzie EJ, Siegel JH, Shapiro S, Moody M, and Smith RT. Functional recovery and medical costs of trauma: An analysis by type and severity of injury. J Trauma 1988;28:281-297.

7. Rivara FP, Grossman DC, and Cummings P. Injury Prevention (first of two parts). NEJM 1997;337:543-548.

8. Rivara FP, Grossman DC, and Cummings P. Injury prevention (second of two parts). NEJM 1997;337:613-618.

9. Elliott DC and Rodriguez A. Cost effectiveness in surgery. Surg Clin N Am 1996;76:47-62.

10. Mann NC, Mullins RJ, MacKenzie EJ, Jurkovich GJ, and Mock $\mathrm{CN}$. Systematic review of published evidence regarding trauma system effectiveness. J Trauma 1999;47:S25-S33.

11. Harlan LC, Harlan WR, and Parsons PE. The economic impact of injuries: A major source of medical costs. Am J Pub Health 1990;80:453.

12. Miller TR and Levy DT. The effect of regional trauma care systems on costs. Arch Surg 1995;130:188-193.

13. Eastman AB, Lewis FR, Champion HR, and Mattox KL. Regional Trauma system design: critical concepts. Am J Surg 1987; $154: 79-87$.

14. Eastman AB. Blood in our streets. The status and evolution of trauma care systems. Arch Surg 1992;127:677-681.
15. Eastman AB, Schwab CW, Annest JL, Aprahamian C, Beachley $\mathrm{M}$, Browner B, and et al. Position paper on trauma care systems. J Trauma 1992;32:127-129.

16. Boyd DR. Trauma-A controllable disease in the 1980's (Fourth Annual Stone Lecture, American Trauma Society). J Trauma 1980;20:14-24.

17. Eggold R. Trauma care regionalization: a necessity (editorial. J Trauma 1983;23:260-262.

18. Farmer TA. Trauma center organization and operation in academic health centers. Am J Emerg Med 1985;3:244-246.

19. Trunkey DD. Trauma. Scientific American 1983;249:28-35.

20. McMurtry RY, Nelson WR, and de la Roche MR. Current concepts in trauma: 1. Principles and directions for development. CMAJ 1989;141:529-533.

21. Rutledge R. The goals, development, and use of trauma registries and trauma data sources in decision making in injury. Surg Clin North Am 1995;75:305-326.

22. Conference on Injury in America. Public Health Rep 1987;102:577.

23. Waller JA. Emergency care for fatalities from injury and illness in the nonhighway setting. J Trauma 1973;13:54-60.

24. Baker CC, Oppenheimer L, Stephens B, Lewis FR, and Trunkey DD. Epidemiology of trauma deaths. Am J Surg 1980;140:144150

25. Trunkey DD. Initial treatment of patients with extensive trauma. NEJM 1991;324:1259-1263.

26. Maull KI and Esposito TJ. Trauma System Design. Chapter 4. Trauma System Design. Mattox KL, Feliciano DV, and Moore EE. Fourth Edition ed. New York: McGraw-Hill Companies Inc., 2000.

27. Beebe GW and DeBakey ME. Battle Casualties. Springfiel, Illinois: Charles C Thomas, 1952.

28. Zollinger RW. Traffic injuries - A surgical problem. Arch Surg 1955;70:694-700.

29. Cales RH, Anderson PG, and Heilig RW. Utilization of medical care in Orange County: the effect of implementation of a regional trauma system. Ann Emerg Med 1985;14:853-858.

30. Trunkey DD. Trauma care systems. Emerg Med Clin N Am 1984;2:913-922.

31. Robertson LS. Injury Epidemilogy. second edition ed. New York: Oxford University Press, 1998.

32. Olson CJ, Brand D, Mullins RJ, Harrahill M, and Trunkey DD. Time to death of hospitalized injured patients as a measure of quality of care. J Trauma 2003;55:45-52.

33. Dailey JT, Teter H, and Cowley RA. Trauma center closures: a National assessment. J Trauma 1992;33:539-547.

34. American College of Surgeons, Committee on Trauma. Resources for optimal care of the injured patient: 1999. American College of Surgeons, 1998.

35. Trunkey DD. Regionalization of trauma care. Topics Emerg Med 1981;3:91-96.

36. Aprahamian C, Wolferth CC, Darin JC, McMahon J, and Weitzel-DeVeas. Status of trauma center designation. J Trauma 1989;29:566-570.

37. West JG, Williams MJ, Trunkey DD, and Wolferth CC. Trauma systems. Current status - future challenges. JAMA 1988;259:3597-3600.

38. West JG. An autopsy method for evaluating trauma care. J Trauma 1981;21:32-34.

39. West JG. Validation of autopsy method for evaluating trauma care. Arch Surg 1982;117:1033-1035.

40. MacKenzie EJ, Steinwachs DM, Bone LR, Floccare DJ, Ramzy $\mathrm{AI}$, and The preventable death study group. Inter-rater reliability of perventable death judgments. J Trauma 1992;33:292-303.

41. Cales RH. Medical Audit. Chapter 9. Medical Audit. Cales RH and Heilig RW Jr Rockville, MD: Aspen Systems Corporation, 1986. 
42. American College of Emergency Physicians. Guidelines for trauma care systems. Ann Emerg Med 1987;16:459.

43. American College of Emergency Physicians. Guidelines for transfer of patients. Ann Emerg Med 1985;14:1221.

44. American College of Emergency Physicians. Trauma care systems development, evaluation, and funding. Ann Emerg Med 1999;34:308.

45. Hackey RB. The politics of trauma system development. J Trauma 1995;39:1045-1053.

46. Esposito TJ, Nania J, and Maier RV. State trauma system evaluation: a unique and comprehensive approach. Ann Emerg Med 1992;21:351-357.

47. Boyd DR and Cowley RA. Comprehensive regional trauma/emergency medical services (EMS) delivery systems. World J Surg 1983;7:149-157.

48. Goldfarb MG, Bazzoli GJ, and Coffey RM. Trauma systems and the costs of trauma care. HSR 1996;31:71.

49. Schwab W, Frankel HL, Rotondo MF, Gares DA, Robison EA, Haskell RM, and et al. The impact of a true partnership between a university level I trauma center and a level II trauma center on patient transfer practices. J Trauma 1998;44:815-820.

50. Bazzoli GJ, Madura KJ, Cooper GF, MacKenzie EJ, and Maier RV. Progress in the development of trauma systems in the United States: results of a national survey. JAMA 1995;273:395-401.

51. Cone JB. Tertiary trauma care in a rural state. Am J Surg 1990;160:652-658.

52. American Trauma Society Supported by the U.S.Department of Transportation, National Highway Traffic Safety Administration. Trauma System Agenda for the Future. 2002.

53. Boyd DR, Pizzano WA, Romano TL, Stiegmann GV, and Nyhus LM. Regionalization of trauma patient care: the Illinois experience. Surg Annu 1975;7:25-52.

54. Waller JA. Emergency health services in areas of low population density. JAMA 1969;207:2255-2258

55. American College of Surgeons. Advanced Trauma Life Support for Doctors (ATLS) Course Manual. Sixth Edition ed. Chicago, IL: American College of Surgeons, 1997.

56. Lyle DM, Thomson PC, Deane SA, and Coulon LA Regionalization of trauma services in Western Sydney: predicted effect on ambulance and hospital utilization rates. Aust NZ J Surg 1991;61:589-596.

57. Lyle DM, Thompon PC, Coulon LA, Berry G, and Kim CM Trauma triage in Western Sydney: results of a pilot study. Aust NZ J Surg 1990;60:953-958.

58. Sampalis JS, Denis R, Frechette P, Brown R, Fleiszer D, and Mulder D. Direct transport to tertiary trauma centers versus transfer from lower level facilities: impact on mortality and morbidity among patients with major trauma. J Trauma 1997;43:288-296.

59. Arroyo JS and Crosby LA. Basic rescue and resuscitation. Trauma System concept in the United States. Clinical Orthopaedics and Related Research 1995;318:11-16.

60. Thompson CT. The emergency physician, the trauma surgeon, and the trauma center. Ann Emerg Med 1983;12:235-237.

61. Rutledge R, Fakhry SM, Meyer M, Sheldon GF, and Baker CC. An analysis of the association of trauma centers with per capita hospitalizations and death rates from injury. Ann Surg 1993;218:521-524.

62. Hammond JS and Breckenridge MB. Longitudinal analysis of the impact of a level 1 trauma center designation at a university hospital. J Am Coll Surg 1999;188:217-224.

63. Schwartz RJ, Jacobs LM, and Yaezel D. Impact of pre-trauma center care on length of stay and hospital charges. J Trauma 1989;29:1611-1615.

64. Robertson R, Mattox R, Collins T, Parker-Mills C, Eidt J, and Cone J. Missed injuries in a rural area trauma center. Am J Surg 1996;172:567-568.
65. Allen DM, Hicks G, and Bota GW. Outcomes after severe trauma at a Northern Canadian regional trauma centre. Can J Surg 1998;41:53-58.

66. Lowe DK. Trauma system development: the critical need for regional needs assessments. J Trauma 1999;47:S106-S107.

67. Moore EE. Trauma sysrems, trauma centers, and trauma surgeons-Opportunity in managed competition. J Trauma 1995;39:1-11.

68. Mulder DS. Specialization in surgery - Implications for traumarelated disciplines. Bull Am Coll Surg 1988;73:15.

69. Hoyt DB, Moore EE, Shackford SR, Holcroft JW, and Jurkovich GJ. Trauma surgeon's leadership role in the development of trauma systems (abstract). J Trauma 1999;46:1142.

70. Youmans RL and Brose RA. A basic for classifying hospital emergency services. JAMA 1970;213:1647-1651.

71. Clemmer TP, Orme JF, Thomas FO, and Brooks KA. Outcome of critically injured patients treated at level I trauma centers versus full-service community hospitals. Crit Care Med 1985;13:861-863.

72. Rutledge R, Messick J, Baker CC, Rhyne S, Butts J, Meyer A, and Ricketts T. Multivariate population-based analysis of the association of county trauma centers with per capita county trauma death rates. J Trauma 1992;33:29-38.

73. Smith JS, Martin LF, Young WW, and Macioce DP. Do trauma centers improve outcome over non-trauma centers: the evaluation of regional trauma care using discharge abstract data and patient management categories. J Trauma 1990;30:1533-1538.

74. Piontek FA, Coscia R, Marselle CS, Korn RL, and Zarling EJ. Impact of American college of surgeons verification on trauma outcomes. J Trauma 2003;54:1041-1047.

75. DiRusso S, Holly C, Kamath R, Cuff S, Cuff S, Sullivan T, Scharf $\mathrm{H}$, and et al. Preparation and achievement of American college of surgeons level I trauma verification raises hospital performance and improves patient outcome. J Trauma 2001;51:294-300.

76. Simons RK, Kasic S, Kirkpatrick AW, Vertesi L, Phang T, and Appleton L. Relative improtance of designation and accreditation of trauma centers during evolution of a regional trauma system (abstract). 2001.

77. Simons R, Kasic S, Kirkpatrick A, Vertesi L, Phang T, and Appleton L. Relative importance of designation and accreditation of trauma centers during evolution of a regional trauma system. J Trauma 2002;52:827-834.

78. Ehrlich PF, Rockwell S, Kincaid S, and Mucha P. American College of Surgeons, Committee on Trauma verification review: does it really make a difference? J Trauma 2002;53:811-816.

79. Pasquale MD, Peitzman AB, Bednarski J, and Wasser TE. Outcome analysis of Pennsylvania trauma centers: Factors predictive of nonsurvival in seriously injured patients. J Trauma 2001;50:465-474.

80. Nathens AB, Jurkovich GJ, Maier RV, Grossman DC, MacKenzie EJ, Moore M, and Rivara FP. Relationship between trauma center volume and outcomes. JAMA 2001;285:1164-1171.

81. Smith RF, Frateschi L, Sloan EP, Campbell L, Kreig R, Edwards LC, and Barrett JA. The impact of volume on outcome in seriously injured trauma patients: two years' experience of the Chicago trauma system. J Trauma 1990;30:1066-1076.

82. Konvolinka CW, Copes WS, and Sacco WJ. Institution and persurgeon volume versus survival outcome in Pennsylvania's trauma centers. Am J Surg 1995;170:333-340.

83. Pasquale MD, Peitzman AB, and Wasser TE. Outcome analysis of level 1 and 2 trauma centers (TC's). J Trauma 1998;45:189.

84. London JA and Batistella FD. Is there a relationship between trauma center volume and mortality? J Trauma 2003;54:16-25. 
85. Cooper A, Hannan EL, Bessey PQ, Farrell LS, Cayten CG, and Mottley L. An examination of the volume-mortality relationship for New York State trauma centers. J Trauma 2000;48:16-24.

86. Tepas JJ, Patel JC, DiScala C, Wears RL, and Veldenz HC. Relationship of trauma patient volume to outcome experience. Can a relationship be defined? J Trauma 1998;44:827-831.

87. Richardson JD, Schmieg R, and Boaz P. Impact of trauma attending surgeon case volume on outcome: is more better? $\mathrm{J}$ Trauma 1998;44:266-272.

88. Hoffer EP. Emergency Medical Services, 1979. NEJM 1979;301:1118-1121.

89. Trafton PG and Trunkey DD. Regionalization of trauma care (letter). NEJM 1980;302:1094-1095.

90. Van Wagoner FH. Died in hospital: a three year study of deaths following trauma. J Trauma 1961;1:401-408.

91. Wright CS, McMurtry RY, Hoyle M, and Pickard J. Preventable deaths in mulitple trauma: review of deaths at Sunnybrooke Medical Centre Trauma Unit. CJS 1983;26:20-23.

92. Kreis DJ, Plasencia G, Augenstein D, Davis JH, Echenique M, Vopal J, and et al. Preventable trauma deaths: Dade County, Florida. J Trauma 1986;26:649-654.

93. Sampalis JS, Lavoie A, Williams JI, Mulder DS, and Kalina M. Standardized mortality ratio analysis on a sample of severely injured patients form a large Canadian city without regionalized trauma care. J Trauma 1992;33:205-212.

94. Lowe DK, Gately HL, Goss JR, Frey CF, and Peterson CG. Patterns of death, complication and errors in the management of motor vehicle accident victims: implications for a regional system of trauma care. J Trauma 1985;28:503-509.

95. Urbach DR, Bell CM, and Austin PC. Differences in operative mortality between high-and low-volume hospitals in Ontario for 5 major surgical procedures: estimating the number of lives potentially saved through regionalization. CMAJ 2003;168:1409-1414.

96. Gross M. Allocation of scarce resources: assessment and impact. CJS 2002;45:8.

97. Brackstone M, Doig GS, and Girotti MJ. Surgical case costing: trauma is underfunded according to resource intensity wieghts. CJS 2002;45:57-62.

98. Birkmeyer JD, Siewers AE, Finlayson EVA, Stukel TA, Lucas FL, Batista I, and et al. Hospital volume and surgical volume in the United States. NEJM 2002;346:1128-1137.

99. Dudley RA, Johansen KL, Brand R, Rennie DJ, and Milstein A. Selective referral to high-volume hospitals : estimating potentially avoidable deaths. JAMA 2000;283:1159-1166.

100. Hemmelgarn BR, Ghali WA, and Quan H. A case study of hospital closure and centralization of coronary vascular procedures. CMAJ 2001;164:1431-1435.

101. Sibbald B. Move to close low-volume surgical sites gaining spee. CMAJ 2002;167:177.

102. Wexler MJ. More procedures, better quality of care? Is there a case for regionalization of pancreatic resection for neoplasm? CMAJ 1999;160:671-673.

103. Simunovic M, To T, Theriault M, and Langer B. Relation between hospital surgical volume and outcome for pancreatic resection for neoplasm in a publicly funded healthcare system. CMAJ 1999;160:643-648.

104. Thoburn E, Norris P, Flores R, Goode S, Rodriguez E, Adams V, Campbell S, Albrink M, and Rosemurgy A. System care improves trauma outcome: Patient care errors dominate reduced preventable death rate. J Emerg Med 1993;11:135-139.

105. Boyd DR, Mains KD, and Flashner BA. A systems approach to statewide emergency medical care. J Trauma 1973;13:276-284.

106. Alexander RH, Pons PT, Krischer J, and Hunt P. The effect of advanced life support and sophisticated hospital systems on motor vehicle mortality. J Trauma 1984;24:486-490.

107. Hulka F, Mullins RJ, Mann NC, Hedges JR, Rowland D, Worrall $\mathrm{WH}$, and et al. Influence of a statewide trauma system on pediatric hospitalization and outcome. J Trauma 1997;42:514-519.
108. Kane G, Wheeler NC, Cook S, Englehardt R, Pavey B, Green K, and et al. Impact of the Los Angeles County trauma system on the survival of seriously injured trauma patients. J Trauma 1992;32:576-583.

109. Mullins RJ, Veum-Stone J, Helfand M, Zimmer-Genbeck M, Hedges JR, Southard PA, and Trunkey DD. Outcome of hospitalized injured patients after institution of a trauma system in an urban area. JAMA 1994;271:1919-1924.

110. Mullins RJ, Veum-Stone J, Hedges JR, Zimmer-Gembeck MJ, Mann C, Southard PA, and et al. Influence of a statewide trauma system on location of hospitalization and outcome of injured patients. J Trauma 1996;40:536-546.

111. Mullins RJ, Mann NC, Hedges JR, Worrall W, and Jurkovich GJ. Preferential benefit from implementation of a statewide trauma system in one of two adjacent states. J Trauma 1998;44:609-617.

112. Mullner R and Goldberg J. An evaluation of the Illinois trauma system. Med Care 1978;16:140-151.

113. Ornato JP, Craren EJ, Nelson NM, and Kimball KF. Impact of improved emergency medical services and emergency trauma care on the reduction in mortality from trauma. J Trauma 1985;25:575-579.

114. Rogers FB, Shackford SR, Hoyt DB, Camp L, Osler TM, Mackersie RC, and Davis JW. Trauma deaths in a mature urban vs rural trauma system. Arch Surg 1997;132:376-382.

115. Mullins RJ and Mann NC. Population-based research assessing the effectiveness of trauma systems. J Trauma 1999;47:S59-S66.

116. Shakford SR, Mackersie RC, Hoyt DB, Baxt WG, Eastman AB, Hammill FN, Knotts B, and Virgilio RW. Impact of a trauma system on outcome of severely injured patients. Arch Surg 1987;122:523-527.

117. Champion HR, Copes WS, Sacco WJ, Lawnick MM, Keast SL, Bain LW, and et al. The major trauma outcome study: Establishing National norms for trauma care. J Trauma 1990;30:1356-1365.

118. Neuman TS, Bockman MA, Moody P, Dunford JV, Griffith LD, Guber SL, Guss DA, and Baxt WG. An autopsy study of traumatic deaths. Am J Surg 1982;144:722-727.

119. Guss DA, Meyer FT, Neuman TS, Baxt WG, Dunford JV, Griffith LD, and Guber SL. The impact of a regionalized trauma system on trauma care in San Diego County. Ann Emerg Med 1989;18:1141-1145.

120. West JG. An autopsy method for evaluating trauma care. J Trauma 1981;21:32-34.

121. Shackford SR, Hollingsworth-Fridlund P, McArdle M, and Eastman AB. Assuring quality in a trauma system - the medical audit committee: composition, cost and results. J Trauma 1987;27:866-875.

122. Shackford SR, Hollingsworth-Fridlund P, Cooper GF, and Eastman AB. The effect of regionalization upon the quality of trauma care as assessed by concurrent audit before and after institution of a trauma system: a preliminary report. J Trauma 1986;26:812-820.

123. Mann NC, Hedges JR, Sandoval R, Worrall W, Zechnich AD, Jurkovich GJ, and Mullins RJ. Trauma system impact on admission site- A comparison of two states. J Trauma 1999;46:631-637.

124. Hedges JR. Summary of the discussion: what have we learned about population-based investigations. J Trauma 1999;47:S67S68.

125. Cayten CG, Quervalu I, and Agarwal N. Fatality analysis reporting system demonstrates association between trauma system initiatives and decreasing death rates. J Trauma 1999;46:751-756.

126. Nathens AB, Jurkovich G, Cummings P, Rivara FP, and Maier RV. Effectiveness of state trauma systems - A National evaluation. J Trauma 1999;47:221.

127. Nathens AB, Jurkovich GJ, Cummings P, Rivara FP, and Maier $\mathrm{RV}$. The effect of organized systems of trauma care on motor vehicle crash mortality. JAMA 2000;283:1990-1994. 
128. Clark DE. Trauma system evaluation using the fatality analysis reporting system. J Trauma 2003;54:1199-1204.

129. Mullins RJ. Editiorial comment - Trauma systems evaluation using the fatality reporting system. J Trauma 2003;54:1204.

130. Jurkovich GJ and Mock C. Systematic review of trauma system effectiveness based on registry comparisons. J Trauma 1999;47:S46-S55.

131. Mock C, Jurkovich GJ, nii-Amon-Kotei D, Arreola-Risa C, and Maier R. Trauma mortality patterns in three Nations at different economic levels - Implications for global trauma system development. J Trauma 1997;43:193.

132. Mock CN, Adzotor KE, Conklin E, Denno DM, and Jurkovich GJ. Trauma outcomes in the rural developing world: comparison with an urban level I trauma center. J Trauma 1993;35:518-523.

133. Mullins RJ and Mann NC. Introduction to the academic symposium to evaluate evidence regarding the efficacy of trauma systems. J Trauma 1999;47:S3-S7.

134. Hunt RC. Reflections on the Skamania conference: An emergency physician's perspective. J Trauma 1999;47:S108.

135. Atweh NA. Toward the all-inclusive trauma system. J Trauma 1999;47:S109.

136. Mullins RJ and Mann NC. Development of a systematic review of published evidence regarding the efficacy of trauma systems. J Surg Outcomes 1998;1:53.

137. Peitzman AB, Courcoulas AP, Stinson C, Udekwu AO, Billiar TR, and Harbrecht BG. Trauma center maturation - Quantification of process and outcome. Ann Surg 1999;230:87-94.

138. Sampalis JS, Denis R, Lavoie A, Frechette P, Boukas S, Nikolis $\mathrm{A}$, and et al. Trauma care regionalization: A process-outcome evaluation. J Trauma 1999;46:565-581.

139. Barquist E, Pizzutiello M, Tian L, Cox C, and Bessey P. Effect of trauma system maturation on mortality rates in patients with blunt injuries in the Finger Lakes Region of New York State. J Trauma 2000;49:63-70.

140. O'Keefe GE, Jurkovich GJ, Copass M, and Maier RV. Ten-year trend in survival and resource utilization at a level I trauma center. Ann Surg 1999;229:409-415.

141. Sampalis JS, Lavoie A, Williams JI, Mulder DS, and Kalina M. Impact of on-site care, pre-hospital time, and level of in-hospital care on survival in severely injured patients. J Trauma 1993;34:252-261.

142. Sampalis JS, Lavoie A, Boukas S, Tamim H, Nikolis A, Frechette P, Brown R, Fleiszer D, Denis R, Bergeron E, and Mulder D. Trauma center designation: initial impact on traumarelated mortality. J Trauma 1995;39:232-239.

143. Goldberg J, Levy PS, Gelfand HM, Mullner R, Iverson N, Lemeshow S, and Rothrock J. Factors affecting trauma center utilization in Illinois. Med Care 1981;19:547-565.

144. Liberman M, Mulder D, and Sampalis JS. Increasing Volume of Low Injury Severity Elderly Patients at Level I Trauma Centers: Is There a Need for Triage Modification? Can J Surg. 2003 46:446-52.

145. Hedges JR, Mullins RJ, Zimmer-Gembeck M, Helfand M, and Southard P. Oregon trauma system: change in intial admission site and post-admission transfer of injured patients. Acad Emerg Med 1994;1:218-226.

146. Esposito TJ, Offner PJ, Jurkovich GJ, Griffith J, and Maier RV.
Do prehospital trauma center triage criteria identify major trauma victims? Arch Surg 1995;130:171-176.

147. Báez AA, Lane PL, and Sorondo B. System compliance with out-ofhospital trauma triage criteria. J Trauma 2003;54:344-351.

148. American College of Surgeons. Advanced Trauma Life Support for Doctors (ATLS). Sixth Edition ed. Chicago, IL: American College of Surgeons, 1997.

149. Champion HR, Sacco WJ, Hannan DS, Lepper RL, Atzinger ES, CopesWS, and Prall RH. Assessment of injury severity: the triage index. Crit Care Med 1980;8:201-208.

150. Gormican SP.CRAMS scale: field triage of trauma victims. Ann Emerg Med 1982;11:132-135.

151. Abernathy JH III, McGwin G Jr, Acker JE III, and Rue LW III. Impact of a voluntary trauma system on mortality, length of stay, and cost at a level I trauma center. Am Surgeon 2002;68:182-192.

152. Nathens AB, Jurkovich GJ, Rivara FP, and Maier RV. Effectiveness of state trauma systems in reducing injury-related mortality: A National evaluation. J Trauma 2000;48:25-31.

153. Ozguc H, Kaya E, Yunuk O, Armagan E, and Tokyay R. Outcome of major trauma in a Turkish university hospital: did integrated approach make a difference? Eur J Emerg Med 2000;7:183-188.

154. Nathens AB, Jurkovich G, Cummings P, Rivara FP, and Maier RV. Effectiveness of state trauma systems - A National evaluation (abstract). J Trauma 1999;47:221.

155. Mullins RJ, Mann NC, Worrall W, Jurkovich GJ, and Hedges JR. Preferential benefit from implementation of a statewide trauma system in one of two adjacent states (abstract). J Trauma 1997;43:122.

156. Nicholl $\mathrm{J}$ and Turner $\mathrm{J}$. Effectiveness of a regional trauma system in reducing mortality from major trauma: before and after study. BMJ 1997;315:1349-1354.

157. Stewart TC, Lane PL, and Stefanits T. An evaluation of patient outcomes before and after trauma center designation using trauma and injury severity score analysis. J Trauma 1995;39:1036-1040.

158. Karsteadt LL, Larsen, CL, and Farmer PD. Analysis of a rural trauma program using the TRISS methodology: A three-year retrospective study. J Trauma 1994;36:395-400.

159. Hill DA, West RH, and Duflou J. Value of the prospective 'before and after' study as a methodology to evaluate outcome in a trauma centre. Aust NZ J Surg 1993;63:940-945.

160. Champion HR, Sacco WJ, and Copes WS. Improvement in outcome from trauma center care. Arch Surg 1992;127:333-338.

161. Shackford SR, Mackersie RC, Hoyt DB, Baxt WG, Eastman AB, Hammill FN, Knotts B, and Virgilio RW. Impact of a trauma system on outcome of severely injured patients. Arch Surg 1987;122:523-527.

162. Cales RH. Trauma mortality in Orange County: the effect of implementation of a regional trauma system. Ann Emerg Med 1984;13:1- 10.

163. West JG, Cales RH, and Gazzaniga AB. Impact of regionalization. The Orange County experience. Arch Surg 1983;118:740-744.

164. West JG, Trunkey DD, and Lim RC. Systems of trauma care. A study of two counties. Arch Surg 1979;114:455-460.

165. Waters JM and Wells CH. The effects of a modern emergency medical care system in reducing automoblile crash deaths. J Trauma 1973;13:645-647.29.

Moishe Liberman MD, is a fourth year resident in the Division of General Surgery at McGill University. He is also a research fellow in the Department of Experimental Surgery at McGill. David S. Mulder MD, MSc, FRCSC is the Chairman of the Division of Cardiothoracic Surgery at the McGill University Health Center, Senior Surgeon at the Montreal General Hospital, and Professor of Surgery at McGill University. John S. Sampalis PhD, is the Head of Surgical Epidemiology at McGill University, an Associate Professor in the Departments of Surgery, Epidemiology and Biostatistics, and an Associate Professor in the Department of Social and Preventive Medicine at Université de Montréal and at Université de Laval. He has been a past recipient of the Medical Research of Canada Scientist award and is currently a senior scientist supported by the Fonds de la recherche en sante du Quebec (FRSQ). 